\title{
Common variable immunodeficiency diagnosed by capsule endoscopy
}

Common variable immunodeficiency (CVID) is the most frequent primary immunodeficiency, characterized by reduced levels of immunoglobulins $[1,2]$. Due to a heterogeneous presentation including a heightened rate of infections, the diagnosis is often delayed for 4-9 years. This delay may contribute to the increased morbidity and mortality in CVID patients $[1,3]$. Gastrointestinal manifestations - most often chronic diarrhea [2] - are seen in up to $50 \%$ of CVID patients. If performed, capsule endoscopy can reveal characteristic extensive nodular lymphoid hyperplasia of the small intestine in up to twothirds of patients [4]. If only upper and lower endoscopy are used in the investigation of chronic diarrhea, nodular lymphoid hyperplasia of the duodenum and the terminal ileum can be misinterpreted as celiac or Crohn's disease [5].

We present the first cases of patients diagnosed with CVID based on capsule endoscopy.

Case 1 was a 40-year-old man with severe symptoms including watery diarrhea, weight loss, recurrent gastrointestinal infections, and grave malnutrition. The symptoms did not fulfill the diagnostic criteria for celiac disease or other spruelike diseases. The patient's IgG level was low and IgA not measurable. Capsule endoscopy showed extensive focal nodular lymphoid hyperplasia throughout the entire small intestine ( $\bullet$ Fig. 1, $\bullet$ Video 1 ). Biopsies from the small bowel revealed intraepithelial lymphocyte infiltration ( Fig.2). Infusion of human IgG improved all gastrointestinal symptoms.

Case 2 was a 60-year-old man with mild symptoms including watery diarrhea, abdominal distension, and recurring upper respiratory tract infections for the previous 25 years. He had low IgG and IgA. Colonic biopsies showed eosinophilia. Upper endoscopy was normal. Capsule endoscopy revealed extensive focal nodular lymphoid hyperplasia throughout the entire small intestine.

\section{Video 1}

Capsule endoscopy video of small intestine showing extensive nodular lymphoid hyperplasia.
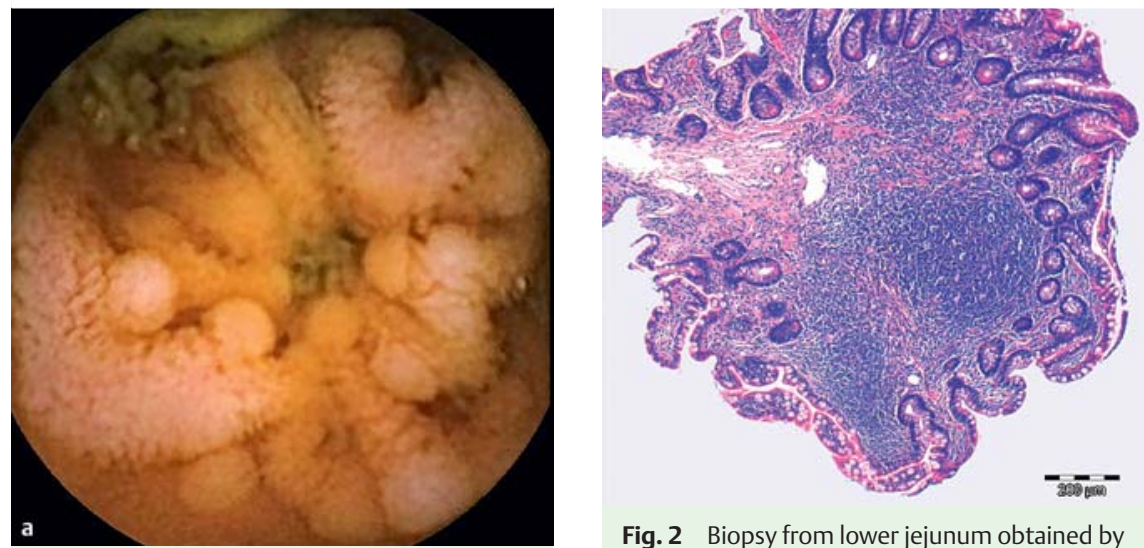

Fig. 2 Biopsy from lower jejunum obtained by double-balloon enteroscopy, showing characteristic histological appearance of nodular lymphoid hyperplasia.

\section{References}

1 Yong PF, Tarzi M, Chua I et al. Common variable immunodeficiency: an update on etiology and management. Immunol Allergy Clin North Am 2008; 28: 367-386

2 Khodadad A, Asghar A, Nima P et al. Gastrointestinal manifestations in patients with common variable immunodeficiency. Dig Dis Sci 2007; 52: 2977-2983

3 Quinti I, Soresina A, Spadaro G et al. Longterm follow-up and outcome of a large cohort of patients with common variable immunodeficiency. J Clin Immunol 2007; 27: 308-316

4 Bayraktar Y, Ersoy O, Sokmensuer C. The findings of capsule endoscopy in patients with common variable immunodeficiency syndrome. Hepatogastroenterology 2007; 54: $1034-1037$

5 Malamut G, Verkarre V, Suarez F et al. The enteropathy associated with common variable immunodeficiency: the delineated frontiers with celiac disease. Am J Gastroenterol 2010; 105: 2262-2275

\section{Bibliography}

DOI 10.1055/s-0030-1257039

Endoscopy 2011; 43: E402

(c) Georg Thieme Verlag KG Stuttgart · New York . ISSN 0013-726X

\section{Endoscopy_UCTN_Code_CCL_1AC_2AH}

\section{Competing interests: None}

\section{K. Theede, M. Thiele, E. Langholz}

Department of Gastroenterology,

Copenhagen University Hospital Gentofte, Hellerup, Denmark

\section{Corresponding author}

\section{K. Theede, MD}

Department of Gastroenterology Copenhagen University Hospital Gentofte Niels Andersensvej 65

2900 Hellerup

Denmark

Fax: +45-39-777121

klaus@theede.se 